\title{
() OPEN ACCESS \\ Late adopters of the electronic health record should move now
}

\author{
Juliet Rumball-Smith (1) , ${ }^{1}$ Kevin Ross, ${ }^{1}$ David W Bates ${ }^{2,3}$
}

${ }^{1}$ Precision Driven Health, Auckland, New Zealand ${ }^{2}$ Department of Medicine, Brigham and Women's Hospital, Boston, MA, United States ${ }^{3}$ Department of Health Policy and Management, Harvard School of Public Health, Boston, MA, United States

\section{Correspondence to} Dr Juliet Rumball-Smith, c/o: Precision Driven Health, 181 Grafton Road, Auckland, 1010, New Zealand:

jrs@health.rumballsmith.nz

Received 27 June 2019 Revised 29 October 2019 Accepted 1 November 2019 Published Online First

15 November 2019
Check for updates

(c) Author(s) (or their employer(s)) 2020. Re-use permitted under CC BY-NC. No commercial re-use. See rights and permissions. Published by BMJ.

To cite: Rumball-Smith J,

Ross K, Bates DW.

BMJ Qual Saf

2020;29:238-240.
Internationally, the last decade has seen the rapid adoption of electronic health records (EHRs) in hospitals and ambulatory care; EHRs are now an accepted enabler of a high-performing health system. ${ }^{1}$ However, the uptake and extent of use of this technology varies substantially. At the country level, Estonia and Sweden are among those nations with mature, interoperable EHRs with high patient access. ${ }^{23}$ In contrast, Switzerland and the UK have only patchy adoption in secondary care, ${ }^{45}$ and New Zealand, an early exemplar of primary care digitisation, ${ }^{6}$ has not yet integrated this information nationally, nor that of hospitals, at scale. Within countries also, there is variation. Even in jurisdictions with high overall rates of adoption, some providers are sophisticated 'super-users' of EHRs, whereas others use only their rudimentary functionalities. ${ }^{7-9}$

The adoption and full employment of an EHR reflects multiple factors, not the least of which are the financial and nonfinancial costs of procuring and implementing these platforms. ${ }^{10}$ Federal-level investment-including policy development, use of legislative levers, and support with resources or subsidies-undoubtedly affects the speed of adoption. ${ }^{11}$ However, even within a maximally supportive environment, there are those who remain 'EHR-wary', citing both uncertain benefit and risk of harm (particularly to clinicians). In this viewpoint, we argue that these EHR concerns may be overstated, irrelevant and/or mitigable, and should neither be used to justify delays in adoption nor full use. We maintain that late adopters and 'under-users'-be they countries, hospitals or individual clinicians-should embrace this technology, and would benefit from prioritising its adoption and comprehensive use.

We acknowledge that the digital patient record itself-that is, the collation of health encounters with multiple providers across space and time for a given healthcare consumer-has not yet yielded the predicted benefits to healthcare quality or patient outcomes in many countries. ${ }^{12}$ That said, in this case the marketing of the 'Electronic Health Record' may be more to blame than the technology itself, as the literal 'record' is potentially both the least beneficial and the most problematic aspect of the technology. If the EHR were a human: the record can be thought of as the 'spine', to which multiple health technology functionalities or 'limbs' attach, and the 'brain' is the data and knowledge obtained from the collation of records from multiple individuals and encounters. Late adopters and under-users should expect benefits to healthcare processes and patients, not principally from the spine, but from the use of the brain and limbs.

Many early EHRs evolved from databases designed for billing or scheduling, to which patient information was appended, and the initial limbs were simplistic innovations required to circumvent issues related to their interconnected table structure. ${ }^{13}$ However, later limbs were developed purposively and with a clinical lens, and these are largely supported by robust empirical evidence of benefit. E-messaging, clinical decision support, patient portals, and health information exchange have all been shown to improve quality of care and patient outcomes, and all have the capacity to contribute more in time. ${ }^{14-18}$ Similarly, the importance of the data brain of the EHR should not be underestimated. Collecting and collating individual-level health and social data enables exploration into healthcare quality and operational inefficiencies, and can inform best management for an individual at the point of care. It can also generate subgroup understandings of health need, utilisation, quality of care 
and outcomes, which are critical for policy making. These data represent assets of both local and national significance.

When weighing up the risk and benefit of EHRs, significant concerns include their impact on clinician satisfaction, their association with clinician burn-out, ${ }^{19}$ and their potential to decrease face time spent with the patient. $^{20}$ Clinician burn-out is real and has system impact, and it is possible that EHR vendors and developers have neither sufficiently responded to their clinical users, nor understood the importance of the user experience. ${ }^{21}$ It is also likely that some of the dissatisfaction and burn-out reflects fatigue with ever-changing EHRs. Like many innovations, the EHR technology is not yet stable, and steady incremental revision (driven in part by evolving requirements) has meant that disruption due to the EHR for early adopters has been frequent and repeated, as opposed to a one-time transformation.

However, we suggest late adopters may in fact benefit from the pitfalls already identified by others, in their position to make choices around vendors, products and limbs (the strengths and weaknesses of the various options have become clearer), and to provide supportive environments to their staff. Major vendors have made many improvements in their software, ${ }^{13}$ and smaller developers are rapidly filling in gaps enabled by Application Programming Interfaces (APIs) and web services. Research has provided signposting to the EHR limbs that offer the greatest potential for gains in quality of care (including the reduction of inequities). ${ }^{22}$ The implementation of these functionalities, and those that remove pain points for clinicians in current workflows, should be prioritised, as should design features that improve the user experience and make high quality care 'more effortless'. ${ }^{23}$ We also have information around strategies to mitigate clinician burn-out, including identifying those at risk or having problems, and providing training and support. ${ }^{24}$ Additionally, scribes, and recent advances in natural language processing, voice recognition and sensing, provide new ways of data capture and user interaction that can support providers. ${ }^{24}$

The fundamental reasons to adopt an EHR still hold-access to tools to improve healthcare quality, and to enable population-level understanding. We suggest that late adopters of the EHR, and those who are limited users only, should not further delayremaining on the sidelines is not an effective strategy. Economic analyses show that there are major potential health system savings to be made, ${ }^{25}$ and in the context of finite resources, it may hurt financially not to fully use the technology available. For larger health systems, creating a supportive policy environment may take years, as will implementation of an interoperable system at scale. Finally, further postponement of EHR adoption and full use will also delay the benefit patients may gain from better quality of care and exploration of health data. (Although notably, these factors may be of lesser importance to later adopters than, for example, financial drivers ${ }^{26}$ ). The EHR represents a technology that is here to stay, and is a critical enabler for organisations wanting to become high-performing health systems. However, in contrast to where it came from-usually billing or administration-a contemporary EHR should have patients and the healthcare team at the very centre, with its primary function being to support and drive the delivery of high value and high quality care.

Contributors JR-S had the idea for the article, wrote the initial draft, was responsible for edits and is the guarantor of the final article. KR and DB contributed to drafts and the decision to submit for publication.

Funding The authors have not declared a specific grant for this research from any funding agency in the public, commercial or not-for-profit sectors.

Competing interests KR reports personal fees from Orion Health, and personal fees from Precision Driven Health, outside the submitted work; JR-S reports personal fees from Precision Driven Health, outside the submitted work; DB reports grants and personal fees from EarlySense, personal fees from CDI (Negev), Ltd, other from ValeraHealth, other from Clew, and grants from IBM Watson, outside the submitted work.

Patient consent for publication Not required.

Provenance and peer review Not commissioned; externally peer reviewed.

Data availability statement There are no data in this work.

Open access This is an open access article distributed in accordance with the Creative Commons Attribution Non Commercial (CC BY-NC 4.0) license, which permits others to distribute, remix, adapt, build upon this work noncommercially, and license their derivative works on different terms, provided the original work is properly cited, appropriate credit is given, any changes made indicated, and the use is noncommercial. See: http://creativecommons.org/licenses/by-nc/4. $0 /$.

ORCID iD

Juliet Rumball-Smith http://orcid.org/0000-0001-8090-4955

\section{REFERENCES}

1 The Commonwealth fund international experts Working group on patients with complex needs. Designing a highperforming health care system for patients with complex needs. Ten reccommendations for policymakers. New York: The Commonwealth fund. Available: https://www. commonwealthfund.org/sites/default/files/documents/ media_files_publications_fund_report_2017_aug_roland_10_ recommendations_for_complex_patients_revisedexpanded. pdf2017

2 Moll J, Rexhepi H, Cajander Åsa, et al. Patients' experiences of accessing their electronic health records: national patient survey in Sweden. J Med Internet Res 2018;20:e278.

3 Nøhr C, Parv L, Kink P, et al. Nationwide citizen access to their health data: analysing and comparing experiences in Denmark, Estonia and Australia. BMC Health Serv Res 2017;17:534.

4 Wilson K, Khansa L. Migrating to electronic health record systems: a comparative study between the United States and the United Kingdom. Health Policy 2018;122:1232-9. 
5 De Pietro C, Francetic I. E-Health in Switzerland: the laborious adoption of the federal law on electronic health records (EHR) and health information exchange (HIE) networks. Health Policy 2018;122:69-74.

6 Jha AK, Doolan D, Grandt D, et al. The use of health information technology in seven nations. Int J Med Inform 2008;77:848-54.

7 Cheung CS, Tong EL, Cheung NT, et al. Factors associated with adoption of the electronic health record system among primary care physicians. JMIR Med Inform 2013;1:e1.

8 Gheorghiu B, Hagens S. Measuring interoperable EHR adoption and maturity: a Canadian example. BMC Med Inform Decis Mak 2016;16:8.

9 Rumball-Smith J, Shekelle P, Damberg CL. Electronic health record "super-users" and "under-users" in ambulatory care practices. Am J Manag Care 2018;24:26-31.

10 Fleming NS, Culler SD, McCorkle R, et al. The financial and nonfinancial costs of implementing electronic health records in primary care practices. Health Aff 2011;30:481-9.

11 Adler-Milstein J, Jha AK. HITECH act drove large gains in hospital electronic health record adoption. Health Aff 2017;36:1416-22.

12 Linder JA, Ma J, Bates DW, et al. Electronic health record use and the quality of ambulatory care in the United States. Arch Intern Med 2007;167:1400-5.

13 Evans RS. Electronic health records: then, now, and in the future. Yearb Med Inform 2016;1:S48-61.

14 Ancker JS, Kern LM, Edwards A, et al. Associations between healthcare quality and use of electronic health record functions in ambulatory care. J Am Med Inform Assoc 2015;22:864-71.

15 Fontaine P, Ross SE, Zink T, et al. Systematic review of health information exchange in primary care practices. J Am Board Fam Med 2010;23:655-70.

16 Mishuris RG, Linder JA, Bates DW, et al. Using electronic health record clinical decision support is associated with improved quality of care. Am J Manag Care 2014;20:e445-52.
17 Mold F, de Lusignan S, Sheikh A, et al. Patients' online access to their electronic health records and linked online services: a systematic review in primary care. Br J Gen Pract 2015;65:e141-51.

18 Prgomet M, Li L, Niazkhani Z, et al. Impact of commercial computerized provider order entry (CPOE) and clinical decision support systems (CDSSs) on medication errors, length of stay, and mortality in intensive care units: a systematic review and meta-analysis. J Am Med Inform Assoc 2017;24:413-22.

19 Babbott S, Manwell LB, Brown R, et al. Electronic medical records and physician stress in primary care: results from the MEMO Study. J Am Med Inform Assoc 2014;21:e100-6.

20 Tai-Seale M, Olson CW, Li J, et al. Electronic health record logs indicate that physicians split time Evenly between seeing patients and desktop medicine. Health Aff 2017;36:655-62.

21 Kaipio J, Lääveri T, Hyppönen H, et al. Usability problems do not heal by themselves: national survey on physicians' experiences with EHRs in Finland. Int J Med Inform 2017;97:266-81.

22 Rumball-Smith J, Bates DW. The electronic health record and health it to decrease racial/ethnic disparities in care. J Health Care Poor Underserved 2018;29:58-62.

23 Vaughn VM, Linder JA. Thoughtless design of the electronic health record drives overuse, but purposeful design can nudge improved patient care. BMJ Qual Saf 2018;27:583-6.

24 Downing NL, Bates DW, Longhurst CA. Physician burnout in the electronic health record era: are we ignoring the real cause? Ann Intern Med 2018;169:50-1.

25 Nuckols TK, Asch SM, Patel V, et al. Implementing computerized provider order entry in acute care hospitals in the United States could generate substantial savings to Society. Jt Comm J Qual Patient Saf 2015;41:341-50.

26 Jamoom EW, Patel V, Furukawa MF, et al. EHR adopters vs. non-adopters: impacts of, barriers to, and federal initiatives for EHR adoption. Healthc 2014;2:33-9. 